\title{
An ongoing search for potential targets and therapies for lethal sepsis
}

\author{
Guo-qiang Bao ${ }^{1,2,3 \dagger}$, Li He ${ }^{4 \dagger}$, David Lee ${ }^{1}$, John D'Angelo ${ }^{1}$ and Hai-chao Wang ${ }^{1,2^{*}}$
}

\begin{abstract}
Sepsis, which refers to a systemic inflammatory response syndrome resulting from a microbial infection, represents the leading cause of death in intensive care units. The pathogenesis of sepsis remains poorly understood although it is attributable to dysregulated immune responses orchestrated by innate immune cells that are sequentially released early (e.g., tumor necrosis factor(TNF), interleukin-1(IL-1), and interferon- $\gamma($ IFN- $\gamma)$ ) and late (e.g., high mobility group box 1(HMGB1)) pro-inflammatory mediators. As a ubiquitous nuclear protein, HMGB1 can be passively released from pathologically damaged cells, thereby converging infection and injury on commonly dysregulated inflammatory responses. We review evidence that supports extracellular HMGB1 as a late mediator of inflammatory diseases and discuss the potential of several Chinese herbal components as HMGB1-targeting therapies. We propose that it is important to develop strategies for specifically attenuating injury-elicited inflammatory responses without compromising the infection-mediated innate immunity for the clinical management of sepsis and other inflammatory diseases.
\end{abstract}

Keywords: Innate immune cells, Pathogen-associated molecular pattern molecules, High mobility group box 1, Herbal components, Sepsis, Autophagy, Endocytosis, Double-stranded RNA-activated protein kinase R

\section{Introduction}

Cohabitating with various microbes, mammals have developed multiple strategies for combatting microbial infections. As the first layer of defense, the epithelial barriers effectively limit the access and growth of the majority of pathogens. If they are breached, innate immune cells immediately launch biological responses, termed "inflammation," to confine and remove these pathogens [1]. These inflammatory responses are usually appropriately propagated and often result in the successful elimination of the invading pathogens. If unsuccessful, the invading pathogens can leak into the bloodstream, triggering a widespread and systemic inflammatory response, termed "sepsis." Sepsis, which refers to a systemic inflammatory response syndrome resulting from a microbial infection, represents the leading cause of death in intensive care units. As a continuum of increasing clinical severity, "severe sepsis" is often associated with one or more acute

\footnotetext{
* Correspondence: hwang@nshs.edu

${ }^{\dagger}$ Equal contributors

'Department of Emergency Medicine, North Shore University Hospital,

Manhasset, NY 11030, USA

${ }^{2}$ The Feinstein Institute for Medical Research, 350 Community Drive,

Manhasset, NY 11030, USA

Full list of author information is available at the end of the article
}

organ dysfunctions [2]. Despite recent advances in antibiotic therapy and intensive care, the overall mortality rate of severe sepsis remains high [3].

The inflammatory responses are first initiated by innate immune cells, such as macrophages and monocytes. These innate immune cells are equipped with pattern recognition receptors, such as the Toll-like receptors (TLRs), TLR2, TLR3, TLR4, and TLR9 [4-8], for various pathogen-associated molecular patterns (PAMPs), such as bacterial peptidoglycan, double-stranded RNA, endotoxin, and CpG-DNA $[9,10]$. The engagement of various PAMPs with respective receptors triggers the sequential release of early (TNF, IL-1 and IFN- $\gamma$ ) and late (HMGB1) proinflammatory mediators [11-13]. Although early proinflammatory cytokines contribute to the pathogenesis of sepsis [14], their early kinetics of release makes them difficult to target in clinical settings.

\section{Discovery of HMGB1 as a late mediator of lethal sepsis} Approximately 20 years ago, we aimed to search for other late mediators that might contribute to the pathogenesis of lethal sepsis. To identify such mediators, we stimulated macrophages with early cytokines (e.g., TNF) and screened the cell-conditioned medium for proteins 
that were released late. The SDS-PAGE gel electrophoresis analysis revealed the release of $30-\mathrm{kDa}$ protein with an $\mathrm{N}$-terminal amino acid sequence identical to HMGB1 [13], a member of the high mobility group-1 nonhistone chromosomal protein family.

\section{Active HMGB1 Secretion}

HMGB1 is constitutively expressed to maintain a large "pool" of pre-formed protein in the majority of cells $[15,16]$. Bearing two nuclear-localization sequences (NLS), HMGB1 is transported into the nucleus by the nuclear import complexes, thereby maintaining a large nuclear "pool" of pre-formed protein (Fig. 1) [17]. Within the nucleus, HMGB1 binds chromosomal DNA and fulfills its nuclear functions, such as maintaining the nucleosomal structure and regulating gene expression [18]. The disruption of local HMGB1 expression renders animals susceptible to infectious [19] or injurious insults $[20,21]$, indicating an overall beneficial role of intracellular HMGB1 [22]. In response to exogenous PAMPs (dsRNA, CpG-DNA and endotoxin) [13, 23] or endogenous cytokines (interferon (IFN)- $\gamma$, IFN- $\beta$ and cold-inducible RNA-binding protein (CIRP)) [24-26], macrophages/ monocytes actively release HMGB1. If dysregulated, the excessive HMGB1 release adversely contributes to the pathogenesis of infection- and injury-elicited inflammatory diseases.

Lacking a leader signal sequence, HMGB1 cannot be actively secreted via the classical ER-Golgi secretory pathway [13]. Instead, the activated macrophages/ monocytes acetylate and phosphorylate HMGB1 at the nuclear localization or export sequences (NLS or NES) $[22,27-29]$ lead to the sequestration of HMGB1 within cytoplasmic vesicles, which are destined for secreting into the extracellular environment $[16,24,30]$. For instance, in response to exogenous PAMPs (e.g., endotoxin) or endogenous cytokines (e.g., IFNs), innate immune cells acetylate lysine residues $28,29,42,43$, 179,181 , and 183 within the NLS sites lead to the cytoplasmic HMGB1 translocation in a JAK/STAT1-dependent fashion (Fig. 2) [16, 24, 27, 30]. Indeed, the pharmacological inhibition or genetic interference with JAK/STAT1 signaling uniformly inhibits HMGB1 secretion induced by IFN $-\beta$, IFN- $\gamma$ or LPS. Notably, LPS might not directly activate STAT1; however, it may trigger indirect STAT1 activation through the intermediate production of IFNs [31] that are capable of inducing HMGB1 release $[24,25,27]$.

After cytoplasmic translocation, HMGB1 is secreted extracellularly through several pathways, including the

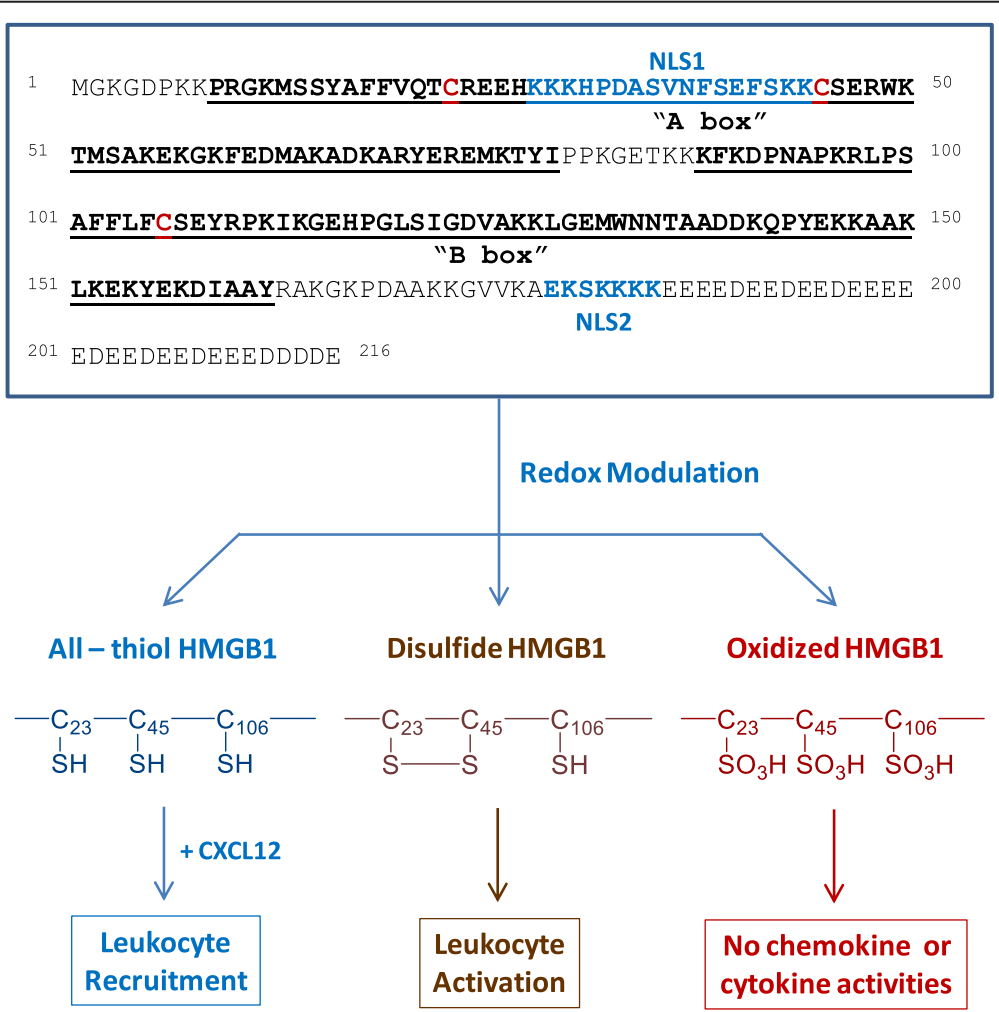

Fig. 1 Redox modulation of HMGB1 immunological activities. The cysteine residues of HMGB1 can be divergently oxidized, which affects its chemokine or cytokine activities. Depending on the redox status, extracellular HMGB1 can either facilitate leukocyte recruitment or activation, resulting in rigorous inflammatory responses (cytokine storm) and organ dysfunction 


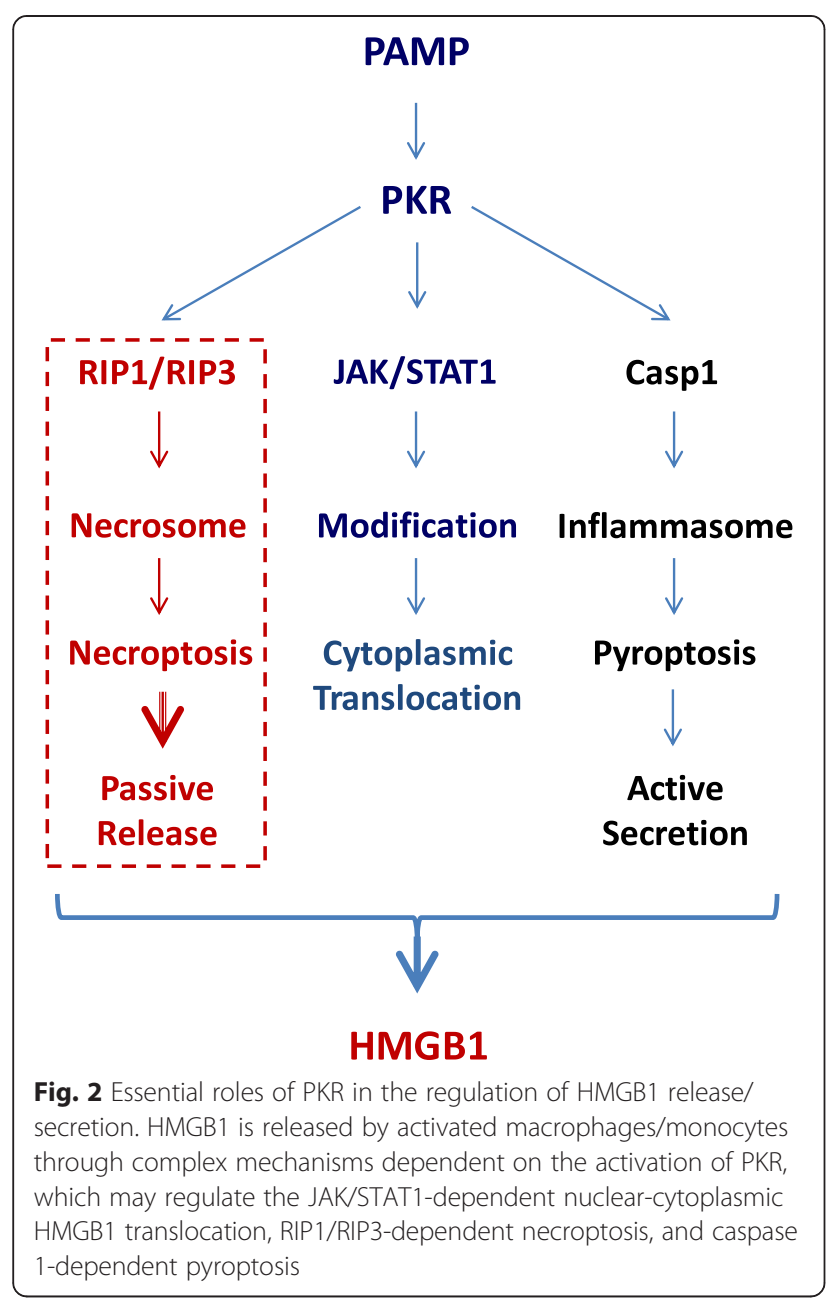

caspase-1/caspase-11-mediated inflammasome activation and pyroptosis (Fig. 2). The pharmacological inhibition with a broad-spectrum caspase inhibitor (Z-VAD-FMK) or the genetic deletion of caspase-1/caspase-11 uniformly reduces HMGB1 secretion from activated macrophages [32, 33]. Similarly, the genetic disruption of the double-stranded RNA-activated protein kinase R (PKR) or the pharmacological inhibition of PKR phosphorylation similarly reduces NLRP3 or NLRP1 agonistsinduced inflammasome activation [34, 35], pyroptosis [34, 35], and HMGB1 release [34]. In light of the likely roles of PKR in the regulation of caspase-1-dependent programmed cell death (pyroptosis) [35] and receptor interacting protein (RIP)1/RIP3-dependent programmed necrosis (necroptosis) (Fig. 2) [36], it is important to explore novel PKR inhibitors that may inhibit HMGB1 release by preventing distinct cell death pathways.

\section{Passive HMGB1 Release}

In addition to active secretion, HMGB1 can be passively released from damaged cells [37] after ischemia/reperfusion [38, 39], trauma $[40,41]$, or toxemia [42-44], thereby serving as damage-associated molecular pattern molecule (DAMP). Necrosis can also be induced by various viruses (e.g., West Nile, salmon anemia, dengue, and influenza viruses) $[45,46]$ and cytokines (e.g., TNF, IFNs) [36, 47]. Extracellular HMGB1 can also trigger caspase1-dependent programmed cell death, pyroptosis, which is characterized by rapid plasma membrane rupture, and the release of proinflammatory intracellular contents (including HMGB1) [48], suggesting a pathogenic role of pyroptosis in HMGB1 release during infection or injury. Thus, infection and injury converge in a common process, i.e., inflammation [49], which is orchestrated by HMGB1 and other proinflammatory mediators (e.g., mitochondrial DNA and CIRP) released by activated immune cells and damaged tissues $[26,50]$.

Once actively secreted or passively released, extracellular HMGB1 binds to various microbial products (e.g., CpG-DNA or LPS), thereby facilitating their recognition by respective receptors to augment inflammatory responses [51]. Harboring three cysteine residues (C23, C45 and C106) that are redox-sensitive, HMGB1 can be modified into three isoforms termed "HMGB1" (all thiol form), "disulfide HMGB1" (partially oxidized), and oxidized HMGB1 (Fig. 1) [52, 53]. The "all-thiol" HMGB1 binds to other chemokines (e.g., CXCL12) and stimulates leukocyte recruitment via the CXCR4 receptor [54] or other signaling molecules [55-57] to the infection or injury sites $[58,59]$. In sharp contrast, disulfide HMGB1 can activate immune cells to produce cytokines/chemokines via TLR4 or other receptors, such as RAGE [51], TLR2, TLR4 [60-62], TLR9 [23, 51], cluster of differentiation 24 (CD24)/Siglec-10 [63], Mac-1 [57], thrombomodulin [64], or single transmembrane domain proteins (e.g., syndecans) [65]. Once fully oxidized, HMGB1 is devoid of either chemokine or cytokine activities (Fig. 1) $[52,53]$. Altogether, these studies suggest that extracellular HMGB1 is a proinflammatory signal to recruit, alert, and activate innate immune cells, thereby sustaining a potentially injurious inflammatory response during sepsis.

\section{Pathogenic role of HMGB1 in sepsis and injury}

Experimental sepsis can be induced by several techniques, including the infusion of exogenous bacterial toxins (endotoxemia) and the disruption of host epithelial barrier, to produce microbial translocation, e.g., cecal ligation and puncture (CLP). In murine models of endotoxemia and CLP-sepsis, HMGB1 is first detected in the circulation $8 \mathrm{~h}$ after the disease onset and is subsequently increased to plateau levels from 16 to $32 \mathrm{~h}$ (Fig. 3a) $[13,66]$. This late appearance of circulating HMGB1 parallels with the onset of animal lethality from endotoxemia or sepsis and distinguishes itself from TNF and other early proinflammatory cytokines [67]. The pathogenic role of HMGB1 in endotoxemia was inferred 


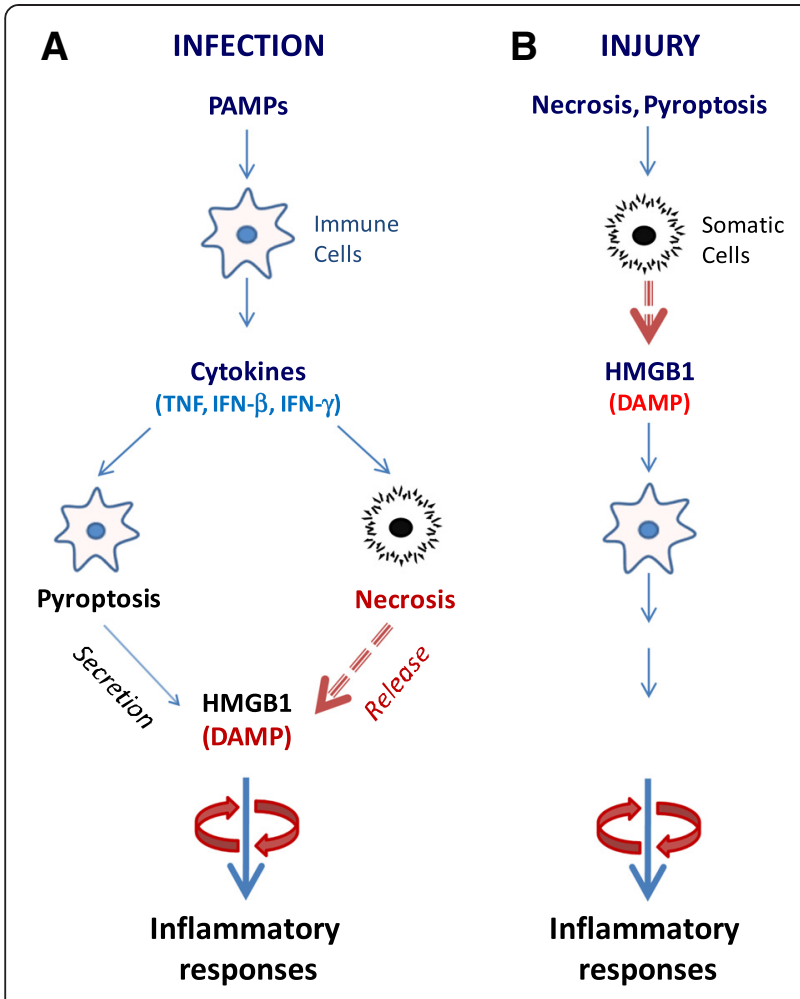

Fig. 3 HMGB1 orchestration of infection- and injury-elicited inflammatory responses. a A microbial infection triggers a systemic inflammatory response by stimulating active HMGB1 secretion or passive release. The disruption of epithelial barrier allows invasion of microbial pathogens, which liberate PAMPs and trigger the production of proinflammatory cytokines. Several proinflammatory cytokines can stimulate innate immune cells to actively secrete HMGB1 and trigger necroptosis that enables passive HMGB1 release. Collectively, extracellular HMGB1 facilitates leukocyte recruitment and activation, amplifying and sustaining rigorous inflammatory responses. $\mathbf{b}$ Injury triggers passive HMGB1 release. After injurious insult, $\mathrm{HMGB} 1$ is passively released by necrotic cells and functions as a DAMP signal that propagates rigorous inflammatory responses that are indistinguishable from infection-elicited inflammation

from studies using HMGB1-neutralizing antibodies, which conferred a dose-dependent protection against endotoxininduced tissue injury and lethality $[13,68]$. In a more clinically relevant CLP-induced sepsis, the delayed administration of HMGB1-specific neutralizing antibodies beginning $24 \mathrm{~h}$ after CLP dose-dependently rescued rodents from lethal sepsis [32, 66, 69]. Moreover, the targeted inhibition of HMGB1 expression in innate immune cells (e.g., macrophages and dendritic cells) reduces systemic HMGB1 accumulation and similarly rescues mice from sepsis [70], supporting HMGB1 as a critical late mediator of experimental sepsis.

Notably, agents capable of inhibiting HMGB1 release [71-73] or action $[13,66]$ confer protection against sepsis, particularly if administered in a delayed fashion to strategically preserve the PAMPs-mediated early inflammatory response. At late-stage infection, the PAMPs- mediated inflammatory response may be accompanied by unintended cell injury and DAMPs release that amplify the cytokine storm to precipitate organ dysfunction (Fig. 3a) [29]. This likelihood is supported by recent findings that HMGB1 is persistently elevated during late-stage sepsis despite the cessation of initial infection [74] and that it contributes to the long-term pathological consequence of sepsis. Although microbial infection-induced sepsis is indistinguishable from sterile injury-elicited systemic inflammatory response syndrome $[75,76]$, it may be more advantageous to develop strategies for specifically attenuating DAMPs-mediated inflammatory responses without compromising the PAMPs-mediated innate immunity.

As a ubiquitous nuclear protein, HMGB1 can be passively released from necrotic cells [37] and can function as a DAMP to elicit inflammatory responses (Fig. 3b). Regardless of the origin, the actively secreted or passively released HMGB1 can similarly alert, recruit, and activate immune cells [49, 77], triggering infection- and injury-elicited systemic inflammatory responses that are often indistinguishable in experimental or clinical settings (Fig. 3) [76]. Indeed, HMGB1-neutralizing antibodies are protective in animal models of ischemia/ reperfusion [38, 78, 79], trauma [80, 81], chemical toxemia [42, 82, 83], atherosclerosis [84], gastric ulcer [85] and hyperoxia [86].

\section{Discovery of Chinese herbs as HMGB1 inhibitors}

The establishment of HMGB1 as a mediator of various inflammatory diseases has prompted the search for inhibitors that can attenuate HMGB1 secretion or action in various experimental settings. As summarized in several recent reviews [22, 29, 87], a growing list of herbal extracts (e.g., Danggui, Mung bean, and Prunella vulgaris) $[88,89]$ and components have been demonstrated to be effective in inhibiting endotoxin-induced HMGB1 secretion. In the present review, we compare the distinct mechanisms by which several herbal therapies effectively inhibit active HMGB1 secretion and action.

\section{Glycyrrhizin (GZA) binds to HMGB1 to inhibit its secretion or action}

Radix Glycyrrhizae (Gancao in Chinese, meaning "sweet root" in Greek or "licorice" in English) has been traditionally used for treating peptic ulcer, hepatitis, and pulmonary bronchitis for many centuries. Its major antiinflammatory component, GZA (Fig. 4a), is protective in animal models of hepatitis [90], hepatic ischemia/reperfusion (I/R) injury [91, 92], endotoxin- and acetaminopheninduced liver injury [93, 94]. Using biochemical techniques, Sakamoto et al. (2001) first demonstrated that GZA directly interacted with HMGB1 and impaired its DNA-binding properties [95]. Subsequently, Mollica et al. (2007) used 
A

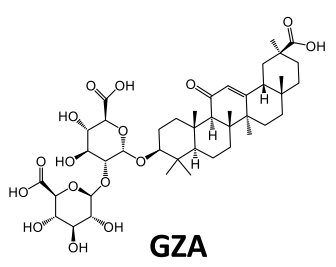

Direct HMGB1 binding

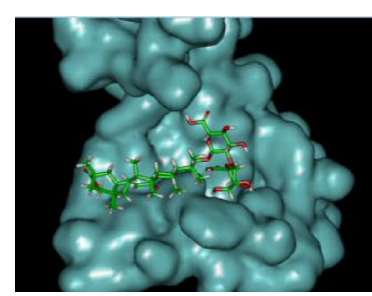

B

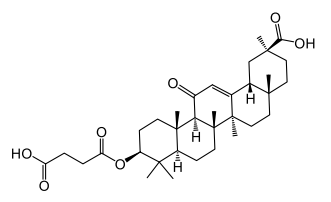

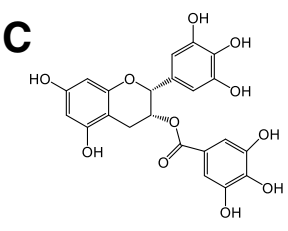

EGCG

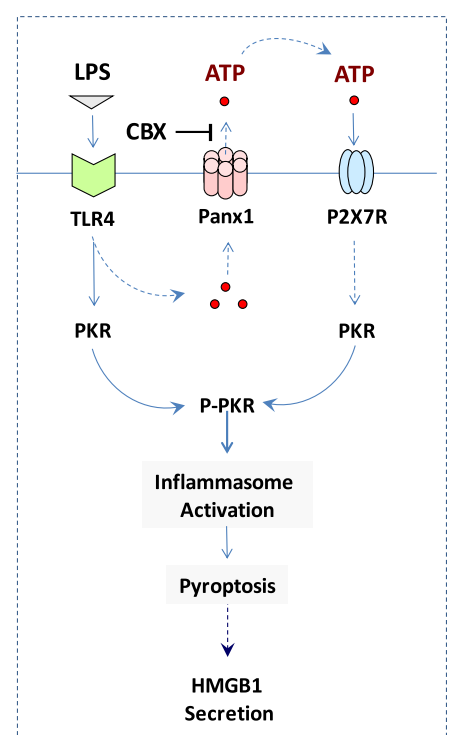

EGCG

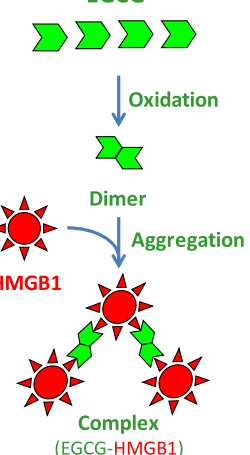

(EGCG-HMGB1)

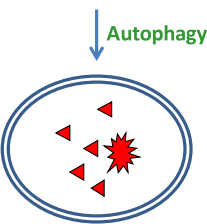

D

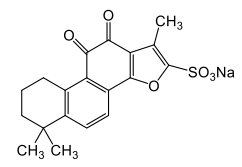

TSN

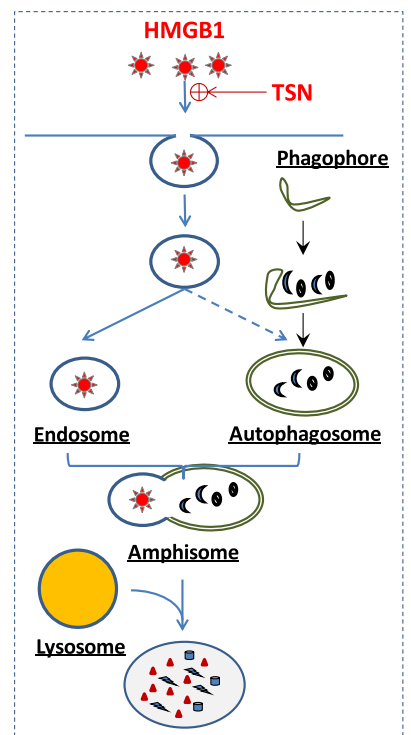

Fig. 4 Distinct HMGB1-inhibition mechanisms of several herbal components. a Direct binding and inhibition of HMGB1 activities. b, c, d Divergent HMGB1 inhibition mechanisms. Different herbal components can inhibit HMGB1 action or release through divergently distinct mechanisms including PKR inactivation (Panel b), autophagic degradation (Panel c), or endocytic HMGB1 uptake and degradation (Panel d)

nuclear magnetic resonance (NMR) and fluorescence techniques to confirm that GZA directly docked into the DNAbinding concaves of HMGB1 boxes (Fig. 4a) [96, 97]. Consistent with these findings, the GZA-mediated protection has been associated with the inhibition of HMGB1 release or its cytokine/chemokine activities [87].

\section{Carbenoxolone (CBX) prevents PKR activation}

Carbenoxolone (CBX) is a chemical derivative of GZA, in which the glucuronic acid is replaced by succinic acid (Fig. 4b). As a medication previously prescribed for esophageal ulceration and inflammation [98], CBX has been demonstrated to dose-dependently inhibit a variety of biological activities, including gap junctions $(50-100 \mu \mathrm{M})$ and panx1 channels $\left(\mathrm{EC}_{50}=1-\right.$ $4 \mu \mathrm{M})[99,100]$. We recently discovered that CBX effectively inhibited LPS-induced HMGB1 secretion, with estimated $\mathrm{IC}_{50}$ at $5 \mu \mathrm{M}$ and $\mathrm{IC}_{100}$ at $10 \mu \mathrm{M}$ [101]. It appears that CBX effectively inhibited endotoxininduced HMGB1 release by preventing PKR upregulation and phosphorylation (Fig. 4b). In light of the findings that CBX $(10 \mu \mathrm{M})$ could effectively inhibit panx-1-mediated ATP release in response to hypoxia [102], sheer stress [103] and low oxygen tension [104], we propose that crude LPS (containing trace amounts of bacterial proteins and nucleic acids) may prime macrophages by up-regulating PKR expression and simultaneously eliciting panx-1-mediated ATP release. The extracellular ATP subsequently binds and activates the purinergic $\mathrm{P}_{2} \mathrm{X}_{7}$ receptor $\left(\mathrm{P}_{2} \mathrm{X}_{7} \mathrm{R}\right)$ [105], which triggers $\mathrm{PKR} /$ inflammasome activation and HMGB1 secretion $[87,106]$. 


\section{Epigallocatechin-3-gallate (EGCG) stimulates autophagic HMGB1 degradation}

Green tea contains a class of biologically active polyphenolic catechins, including the most abundant epigallocatechin-3-gallate (EGCG) (Fig. 4c). At low concentrations, EGCG dose-dependently abrogates LPS-induced HMGB1 secretion, with an estimated $\mathrm{IC}_{50}<1.0 \mu \mathrm{M}$ [72]. Notably, the significant inhibition of HMGB1 secretion is achieved when EGCG is added $2 \mathrm{~h}$ to $6 \mathrm{~h}$ post LPS stimulation [72], suggesting a likelihood of delayed regimen for EGCG treatment. EGCG appears to prevent LPS-induced HMGB1 secretion strategically by destroying HMGB1 in the cytoplasm via a cellular degradation process, autophagy ("self-eating") (Fig. 4c).

EGCG can be trafficked into cytoplasmic vesicles (presumably autophagosomes) within $6 \mathrm{~h}$ and destined to autophagolysosomes within $16 \mathrm{~h}$ [107]. Additionally, EGCG can conjugate to cytoplasmic HMGB1, leading to the formation of EGCG-HMGB1 complexes (dimmer, trimmer, tetramer, and oligomer) (Fig. 4c) [107]. Because these large EGCG-HMGB1 complexes cannot physically pass through the narrow pore of the proteasome barrel of the ubiquitin-proteasome pathway, they trigger the autophagic degradation process. At concentrations effective for inhibiting HMGB1 secretion, EGCG dramatically enhances the formation of autophagosomes [107]. Recently, EGCG has proven to be effective in stimulating autophagy in breast cancer cells [107], hepatocytes [108], retinal pigment epithelial cells [109], and vascular endothelial cells [110]. Given the likelihood that HMGB1 interacts with autophagy regulators (e.g., beclin-1) in the cytoplasm [111, 112], it will be important to investigate whether HMGB1 occupies a critical role in EGCGmediated autophagy. This assessment is relevant because recent studies have indicated that bacterial endotoxin induces significantly less autophagy in HMGB1-deficient macrophages [19].

\section{Tanshinone IIA sodium sulfonate (TSN) stimulates endocytic HMGB1 uptake}

Radix Salviae Miltiorrhizae (Danshen in Chinese) is a medicinal herb that contains several red pigments, including tanshinone I, II, IV, and cryptotanshinone that consist of various anti-inflammatory properties. As a major component (representing $5 \%$ to $6 \%$ of the total dry weight) of Danshen root, tanshinone IIA dosedependently attenuates LPS-induced HMGB1 secretion, with an estimated $\mathrm{IC}_{50}<25 \mu \mathrm{M}$. However, its poor water solubility may adversely affect the bioavailability and therapeutic efficacy of tanshinone IIA [73]. One watersoluble derivative, tanshinone IIA sodium sulfonate (TSN) (Fig. 4d), also dose-dependently inhibits LPS-induced HMGB1 secretion with a lower $\mathrm{IC}_{50}<10 \mu \mathrm{M}$. At doses that completely prevent HMGB1 secretion, TSN does not affect endotoxin-induced release of most other cytokines and chemokines (such as IL-6, IL-12p40/p70, KC, MCP-1, MIP- $1 \alpha$, MIP-2, and TNF), indicating a selectivity for TSN in inhibiting HMGB1 secretion.

Although TSN itself is unable to stimulate autophagic HMGB1 degradation [72], it induces the internalization of exogenous HMGB1 into macrophage cytoplasmic vesicles likely through clathrin- and caveolin-dependent endocytosis (Fig. 4d) [113]. The inhibition of clathrindependent (e.g., chlorpromazine) and caveolin-dependent (e.g., nystatin and indomethacin) endocytosis uniformly attenuates the TSN-mediated HMGB1 uptake. Surprisingly, the depletion of several HMGB1 receptors (e.g., TLR2, TLR4, or RAGE) does not impair TSN-mediated enhancement of HMGB1 uptake, suggesting that other HMGB1-binding cell surface proteins (such as, Mac-1, thrombomodulin, or syndecan) may be required for the TSN-mediated HMGB1 internalization.

Intriguingly, emerging evidence has suggested that cytoplasmic HMGB1 is a key activator of autophagy $[19,111,112]$, supporting a likely link between TSNmediated HMGB1 endocytosis and autophagy. When occurring simultaneously, endosomes can fuse with autophagosomes to form amphisomes [114, 115], which merge with lysosomes to form autolysosomes to degrade the amphisome contents [116]. Thus, endocytosis and autophagy can converge on a common lysosome-dependent pathway, leading to eventual HMGB1 degradation. TSN can likely facilitate endocytosis of exogenous HMGB1, leading to the subsequent HMGB1 degradation via a lysosomedependent pathway (Fig. 4d). It also explains why even when administered several hours after the endotoxin stimulation, TSN can still effectively block HMGB1 secretion.

\section{Therapeutic efficacy of HMGB1-inhibiting herbs}

Current sepsis therapies are largely supportive and limited to a few clinical interventions, including antibiotics, steroidal anti-inflammatory drugs (e.g., hydrocortisone) and early goal-directed therapies (EGDT). For instance, appropriate broad-spectrum antibiotics are often administered to patients to facilitate the elimination of bacterial pathogens [2]; however, the release of bacterial products (e.g., endotoxin or CpG-DNA) may adversely amplify inflammatory responses. Accordingly, anti-inflammatory steroids (e.g., hydrocortisone, methylprednisolone, dexamethasone, and fludrocortisone) are frequently used to modulate the excessive inflammatory response, despite the lack of reproducible efficacy in clinical sepsis trials [117-119]. As a supportive intervention, EGDT employs extremely tight control of numerous physiological parameters (such as central venous pressure, mean arterial blood pressure, central venous oxygen saturation, and hematocrit) with discrete, protocol-driven 
interventions of crystalloid fluids, vasopressors, and blood transfusions. Unfortunately, this simple intervention was ineffective in reducing septic mortality [120, 121], prompting the search for other HMGB1-targeting agents for treating sepsis in humans.

Given that various herbal components are capable of preventing endotoxin-induced HMGB1 secretion, we explored their efficacy in animal models of CLP-induced sepsis. Considering the late and prolonged kinetics of HMGB1 accumulation in experimental sepsis [66], the first dose of HMGB1 inhibitors was administered in a delayed fashion $24 \mathrm{~h}$ after the onset of sepsis. Repetitive intraperitoneal administrations of EGCG [72], TSN [73], or CBX [101] at $24 \mathrm{~h}, 48 \mathrm{~h}$, and $72 \mathrm{~h}$ post CLP significantly increased animal survival rates. When administered orally, EGCG rescued mice from lethal sepsis, significantly increasing animal survival rates from $16 \%$ to $44 \%$ [107]. Intriguingly, we found that EGCG facilitated bacterial elimination in selective organs (e.g., liver and lung) in an animal model of sepsis [122]. Importantly, these herbal components have demonstrated to be beneficial in other models of inflammation, such as ischemia trauma, crush injury, radiation, and chemical toxemia [87]. It is not yet known whether these protective effects are associated with the inhibition of HMGB1 release or chemokine/cytokine activities.

Recently, an herbal remedy consisting of five herbs (Radix Angelicae Sinensis (Danggui in Chinese), Radix Salviae Miltiorrhizae (Danshen in Chinese), Flos Carthami (Honghua in Chinese), Rhizoma Ligustici Chuanxiong (Chuanxiong in Chinese), and Radix Paeoniae Rubra (Chishao in Chinese)) has been developed in China for treating septic patients. This combinational therapy, termed Xuebijing (name in Chinese) has proven to be protective in animal models of sepsis [123] or in patients with sepsis $[124,125]$. Considering the distinct but likely complementary mechanisms, HMGB1 inhibition and other combinational therapy might also be associated with improved therapeutic efficacy. For instance, the induction of autophagy by EGCG may provide a negative feedback regulation of inflammasome activation by eliminating damaged mitochondria [126], removing active inflammasomes [126, 127], and destroying cytoplasmic HMGB1 [107]. It is thus important to test whether improved protection could be achieved by combinational therapy using HMGB1 inhibitors that divergently modulate autophagy (e.g., EGCG) and inflammasome (e.g., CBX). These important studies may pave the road to future clinical studies that explore the therapeutic potential of additional herbal cocktails for treating sepsis and other inflammatory diseases.

\section{Conclusions and outlook}

For complex systemic inflammatory syndromes, it is difficult to translate successful animal studies into clinical applications, in part, because of the pitfalls in the selection of non-feasible therapeutic targets or non-realistic clinical outcome measures, such as survival rates [1]. For instance, therapeutic strategies targeting PAMPs (e.g., endotoxin) [128] or PAMP signaling (e.g., eritoran) [129] fail to improve survival in clinical trials of human sepsis, raising questions regarding the feasibility of PAMPs-blocking agents in the treatment of infectious diseases. However, the investigation of pathogenic cytokines in animal models of diseases has led to the development of successful cytokine-targeting therapeutic strategies (e.g., chimeric anti-TNF monoclonal antibody, infliximab, and a soluble TNF receptors-Fc fusion protein, sTNF-R-Fc, etanercept) for autoimmune diseases, such as rheumatoid arthritis [130]. Thus, there is ongoing research for other clinically feasible therapeutic targets (such as IL-3) and medications for human sepsis [131].

HMGB1, which is secreted from immunologically activated innate immune cells and is released from pathologically damaged cells, functions as a critically important mediator in lethal infection and injury. In animal models of sepsis, HMGB1-neutralizing antibodies or inhibitors can rescue mice from the lethality, particularly if administered in a delayed manner to preserve the potentially beneficial early PAMPs-mediated inflammatory responses [132]. Developing novel strategies for specifically modulating DAMP-elicited injurious inflammatory response without impairing the PAMP-mediated beneficial innate immunity against infection may be possible. Future clinical studies are anticipated to test the efficacy of HMGB1-neutralizing antibodies in the clinical management of human inflammatory diseases.

However, humanized monoclonal antibodies $(\mathrm{mAb})$ are manufactured in low-yield and time-consuming mammalian cells and are thus more expensive than small molecule chemical agents [29]. It is thus essential to develop cost-effective, small molecule agents for the clinical management of human sepsis. One of the most selective HMGB1 inhibitor, TSN, has already been used in China as medication for patients with cardiovascular disorders. The capacity to facilitate endocytic HMGB1 uptake by professional phagocytes may provide the basis for the treatment of both infection- and injury-elicited inflammatory diseases [29]. It is not yet known whether better protection could be achieved by a combinational therapy with several anti-HMGB1 agents. It is thus important to explore the therapeutic potential of these HMGB1-inhibiting agents in future studies.

\section{Abbreviations}

CBX: Carbenoxolone; CIRP: Cold-inducible RNA-binding protein; CLP: Cecal ligation and puncture; DAMP: Damage-associated molecule pattern molecules; EGCG: Epigallocatechin-3-gallate; GZA: Glycyrrhizin; HMGB1: High mobility group box 1; IFN: Interferon; IL: Interleukin; $I_{50}$ : The half maximal inhibitory concentration; LPS: Lipopolysaccharide; NLS: nuclear localization sequence; NLR: Nod-like receptor; PAMP: Pathogen-associated molecular pattern molecule; PKR: Double-stranded RNA-activated protein kinase R; 
RAGE: Receptor for advanced glycation end products; RIP: Receptor interacting protein; STAT1: Signal transducer and activator of transcription 1; TLR: Toll-like receptor; TNF: Tumor necrosis factor; TSN: Tanshinone IIA sodium sulfonate.

\section{Competing interests}

The authors declare that they have no competing interests.

\section{Authors' contributions}

$\mathrm{GB}$ and $\mathrm{HL}$ generated the rough draft; DL and JD provided important comments about the clinical management of human sepsis. HW finalized the manuscript; All authors read and approved the final manuscript.

\section{Acknowledgments}

We are grateful to the peer reviewers for their critical and constructive comments. Work in authors' laboratory was supported by grants from the National Center of Complementary and Alternative Medicine (NCCAM, R01AT005076) and the National Institute of General Medical Sciences (NIGMS, R01GM063075).

\section{Author details}

'Department of Emergency Medicine, North Shore University Hospital, Manhasset, NY 11030, USA. ${ }^{2}$ The Feinstein Institute for Medical Research, 350 Community Drive, Manhasset, NY 11030, USA. ${ }^{3}$ Department of General Surgery, Tangdu Hospital, The 4th Military Medical University, Xi'an, Shaanxi 710032, China. ${ }^{4}$ Department of Ophthalmology, University of Alabama at Birmingham, Birmingham, AL 35294, USA.

\section{Received: 19 March 2015 Accepted: 20 July 2015 Published online: 08 August 2015}

\section{References}

1. Wang H, Zhu S, Zhou R, Li W, Sama AE. Therapeutic potential of HMGB1-targeting agents in sepsis. Expert Rev Mol Med. 2008;10:e32.

2. Dellinger RP, Levy MM, Carlet JM, Bion J, Parker MM, Jaeschke R, et al. Surviving Sepsis Campaign: international guidelines for management of severe sepsis and septic shock: 2008. Crit Care Med. 2008;36:296-327.

3. Angus DC, Linde-Zwirble WT, Lidicker J, Clermont G, Carcillo J, Pinsky MR. Epidemiology of severe sepsis in the United States: analysis of incidence, outcome, and associated costs of care. Crit Care Med. 2001;29:1303-10.

4. Ha T, Lu C, Liu L, Hua F, Hu Y, Kelley J, et al. TLR2 ligands attenuate cardiac dysfunction in polymicrobial sepsis via a phosphoinositide 3-kinasedependent mechanism. Am J Physiol Heart Circ Physiol. 2010;298:H984-91.

5. Gao M, Ha T, Zhang X, Liu L, Wang X, Kelley J, et al. Toll-like receptor 3 plays a central role in cardiac dysfunction during polymicrobial sepsis. Crit Care Med. 2012;40:2390-9.

6. Brightbill HD, Libraty DH, Krutzik SR, Yang RB, Belisle JT, Bleharski JR, et al. Host defense mechanisms triggered by microbial lipoproteins through toll-like receptors. Science. 1999:285:732-6.

7. Poltorak A, He X, Smirnova I, Liu MY, Huffel CV, Du X, et al. Defective LPS signaling in $\mathrm{C} 3 \mathrm{H} / \mathrm{HeJ}$ and $\mathrm{C} 57 \mathrm{BL} / 10 \mathrm{SCC}$ mice: mutations in TIr4 gene. Science. 1998:282:2085-8

8. Hemmi H, Takeuchi O, Kawai T, Kaisho T, Sato S, Sanjo H, et al. A Toll-like receptor recognizes bacterial DNA. Nature. 2000;408:740-5.

9. Akira S, Takeda K. Toll-like receptor signalling. Nat Rev Immunol. 2004:4:499-511.

10. Baggiolini M, Loetscher P. Chemokines in inflammation and immunity. Immunol Today. 2000;21:418-20.

11. Chan ED, Riches DW. IFN-gamma + LPS induction of iNOS is modulated by ERK, JNK/SAPK, and p38 mapk in a mouse macrophage cell line. Am J Physiol Cell Physiol. 2001;280:C441-50.

12. Liu QY, Yao YM. Inflammatory response and immune regulation of high mobility group box-1 protein in treatment of sepsis. World J Emerg Med. 2010;1:93-8.

13. Wang $\mathrm{H}$, Bloom $\mathrm{O}$, Zhang $\mathrm{M}$, Vishnubhakat JM, Ombrellino $\mathrm{M}$, Che J, et al. HMG-1 as a late mediator of endotoxin lethality in mice. Science. 1999:285:248-51.

14. Tracey KJ, Fong Y, Hesse DG, Manogue KR, Lee AT, Kuo GC, et al. Anti-cachectin/ TNF monoclonal antibodies prevent septic shock during lethal bacteraemia. Nature. 1987;330:662-4
15. Chen G, Li J, Qiang X, Czura CJ, Ochani M, Ochani K, et al. Suppression of HMGB1 release by stearoyl lysophosphatidylcholine:an additional mechanism for its therapeutic effects in experimental sepsis. J Lipid Res. 2005;46:623-7.

16. Bonaldi T, Talamo F, Scaffidi P, Ferrera D, Porto A, Bachi A, et al. Monocytic cells hyperacetylate chromatin protein HMGB1 to redirect it towards secretion. EMBO J. 2003;22:5551-60.

17. Kang R, Chen R, Zhang Q, Hou W, Wu S, Cao L, et al. HMGB1 in health and disease. Mol Aspects Med. 2014;40:1-116.

18. Bustin M. At the crossroads of necrosis and apoptosis: signaling to multiple cellular targets by HMGB1. Sci STKE. 2002;2002:E39.

19. Yanai H, Matsuda A, An J, Koshiba R, Nishio J, Negishi H, et al. Conditional ablation of HMGB1 in mice reveals its protective function against endotoxemia and bacterial infection. Proc Natl Acad Sci U S A. 2013;110:20699-704

20. Kang R, Zhang Q, Hou W, Yan Z, Chen R, Bonaroti J, et al. Intracellular Hmgb1 inhibits inflammatory nucleosome release and limits acute pancreatitis in mice. Gastroenterology. 2014;146:1097-107.

21. Huang H, Nace GW, McDonald KA, Tai S, Klune JR, Rosborough BR, et al. Hepatocyte-specific high-mobility group box 1 deletion worsens the injury in liver ischemia/reperfusion: a role for intracellular high-mobility group box 1 in cellular protection. Hepatology. 2014;59:1984-97.

22. Lu B, Wang C, Wang M, Li W, Chen F, Tracey KJ, et al. Molecular mechanism and therapeutic modulation of high mobility group box 1 release and action: an updated review. Expert Rev Clin Immunol. 2014;10:713-27.

23. Ivanov S, Dragoi AM, Wang X, Dallacosta C, Louten J, Musco G, et al. A novel role for HMGB1 in TLR9-mediated inflammatory responses to CpG-DNA. Blood. 2007;110:1970-81.

24. Rendon-Mitchell B, Ochani M, Li J, Han J, Wang H, Yang H, et al. IFN-gamma Induces High Mobility Group Box 1 Protein Release Partly Through a TNF-Dependent Mechanism. J Immunol. 2003;170:3890-7.

25. Kim JH, Kim SJ, Lee IS, Lee MS, Uematsu S, Akira S, et al. Bacterial endotoxin induces the release of high mobility group box 1 via the IFN-beta signaling pathway. J Immunol. 2009;182:2458-66.

26. Qiang X, Yang WL, Wu R, Zhou M, Jacob A, Dong W, et al. Cold-inducible RNA-binding protein CIRP triggers inflammatory responses in hemorrhagic shock and sepsis. Nat Med. 2013;19:1489-95.

27. Lu B, Antoine DJ, Kwan $K$, Lundback $P$, Wahamaa $H$, Schierbeck $H$, et al. JAK/STAT1 signaling promotes HMGB1 hyperacetylation and nuclear translocation. Proc Natl Acad Sci U S A. 2014;111:3068-73.

28. Youn JH, Shin JS. Nucleocytoplasmic shuttling of HMGB1 is regulated by phosphorylation that redirects it toward secretion. J Immunol. 2006;177:7889-97.

29. Wang H, Ward MF, Sama AE. Targeting HMGB1 in the treatment of sepsis. Expert Opin Ther Targets. 2014;18:257-68.

30. Gardella S, Andrei C, Ferrera D, Lotti LV, Torrisi MR, Bianchi ME, et al. The nuclear protein HMGB1 is secreted by monocytes via a non-classical, vesicle-mediated secretory pathway. EMBO Rep. 2002;3:955-1001.

31. Ohmori Y, Hamilton TA. Requirement for STAT1 in LPS-induced gene expression in macrophages. J Leukoc Biol. 2001;69:598-604.

32. Qin $\mathrm{S}$, Wang H, Yuan R, Li H, Ochani M, Ochani K, et al. Role of HMGB1 in apoptosis-mediated sepsis lethality. J Exp Med. 2006;203:1637-42.

33. Lamkanfi M, Sarkar A, Vande WL, Vitari AC, Amer AO, Wewers MD, et al. Inflammasome-dependent release of the alarmin HMGB1 in endotoxemia. J Immunol. 2010;185:4385-92.

34. Lu B, Nakamura T, Inouye K, Li J, Tang Y, Lundback P, et al. Novel role of PKR in inflammasome activation and HMGB1 release. Nature. 2012;488:670-4.

35. Hett EC, Slater LH, Mark KG, Kawate T, Monks BG, Stutz A, et al. Chemical genetics reveals a kinase-independent role for protein kinase $R$ in pyroptosis. Nat Chem Biol. 2013;9:398-405.

36. Thapa RJ, Nogusa S, Chen P, Maki JL, Lerro A, Andrake M, et al. Interferon-induced RIP1/RIP3-mediated necrosis requires PKR and is licensed by FADD and caspases. Proc Natl Acad Sci U S A. 2013;110:E3109-18,

37. Scaffidi P, Misteli T, Bianchi ME. Release of chromatin protein HMGB1 by necrotic cells triggers inflammation. Nature. 2002:418:191-5.

38. Tsung A, Sahai R, Tanaka H, Nakao A, Fink MP, Lotze MT, et al. The nuclear factor HMGB1 mediates hepatic injury after murine liver ischemiareperfusion. J Exp Med. 2005;201:1135-43.

39. Andrassy M, Volz HC, lgwe JC, Funke B, Eichberger SN, Kaya Z, et al. Highmobility group box-1 in ischemia-reperfusion injury of the heart. Circulation. 2008;117:3216-26. 
40. Cohen MJ, Brohi K, Calfee CS, Rahn P, Chesebro BB, Christiaans SC, et al. Early release of high mobility group box nuclear protein 1 after severe trauma in humans: role of injury severity and tissue hypoperfusion. Crit Care. 2009;13:R174. doi:10.1186/cc8152.

41. Peltz ED, Moore EE, Eckels PC, Damle SS, Tsuruta Y, Johnson JL, et al. HMGB1 is markedly elevated within $6 \mathrm{~h}$ of mechanical trauma in humans. Shock. 2009;32:17-22.

42. Zhou RR, Liu HB, Peng JP, Huang Y, Li N, Xiao MF, et al. High mobility group box chromosomal protein 1 in acute-on-chronic liver failure patients and mice with ConA-induced acute liver injury. Exp Mol Pathol. 2012;93:213-9.

43. Antoine DJ, Dear JW, Lewis PS, Platt V, Coyle J, Masson M, et al. Mechanistic biomarkers provide early and sensitive detection of acetaminophen-induced acute liver injury at first presentation to hospital. Hepatology. 2013:58:777-87.

44. Seo YS, Kwon JH, Yaqoob U, Yang L, de Assuncao TM, Simonetto DA, et al. HMGB1 recruits hepatic stellate cells and liver endothelial cells to sites of ethanol induced parenchymal cell injury. Am J Physiol Gastrointest Liver Physiol. 2013;305:G838-48.

45. Chen LC, Yeh TM, Wu HN, Lin YY, Shyu HW. Dengue virus infection induces passive release of high mobility group box 1 protein by epithelial cells. J Infect. 2008:56:143-50.

46. Whilding LM, Archibald KM, Kulbe H, Balkwill FR, Oberg D, McNeish IA. Vaccinia Virus Induces Programmed Necrosis in Ovarian Cancer Cells. Mol Ther. 2013;21:2074

47. Cho YS, Challa S, Moquin D, Genga R, Ray TD, Guildford M, et al. Phosphorylation-driven assembly of the RIP1-RIP3 complex regulates programmed necrosis and virus-induced inflammation. Cell. 2009;137:1112-23.

48. Xu J, Jiang Y, Wang J, et al. Macrophage endocytosis of high-mobility group box 1 triggers pyroptosis. Cell Death Differ. 2014;21:1229-39.

49. Andersson $U$, Tracey KJ. HMGB1 is a therapeutic target for sterile inflammation and infection. Annu Rev Immunol. 2011;29:139-62.

50. Zhang Q, Raoof M, Chen Y, Sumi Y, Sursal T, Junger W, et al. Circulating mitochondrial DAMPs cause inflammatory responses to injury. Nature. 2010;464:104-7.

51. Tian J, Avalos AM, Mao SY, Chen B, Senthil K, Wu H, et al. Toll-like receptor 9-dependent activation by DNA-containing immune complexes is mediated by HMGB1 and RAGE. Nat Immunol. 2007;8:487-96.

52. Venereau E, Casalgrandi M, Schiraldi M, Antoine DJ, Cattaneo A, De Marchis $F$, et al. Mutually exclusive redox forms of HMGB1 promote cell recruitment or proinflammatory cytokine release. J Exp Med. 2012;209:1519-28.

53. Yang $H$, Lundback $P$, Ottosson L, Erlandsson-Harris $H$, Venereau E, Bianch $M E$, et al. Redox modification of cysteine residues regulates the cytokine activity of high mobility group box-1 HMGB1. Mol Med. 2012;18:250-9. doi:10.2119/molmed.2011.00389.

54. Schiraldi M, Raucci A, Munoz LM, Livoti E, Celona B, Venereau E, et al. HMGB1 promotes recruitment of inflammatory cells to damaged tissues by forming a complex with CXCL12 and signaling via CXCR4. J Exp Med. 2012;209:551-63.

55. Yang D, Chen Q, Yang H, Tracey KJ, Bustin M, Oppenheim JJ. High mobility group box-1 protein induces the migration and activation of human dendritic cells and acts as an alarmin. J Leukoc Biol. 2007:81:59-66.

56. Dumitriu IE, Bianchi ME, Bacci M, Manfredi AA, Rovere-Querini P. The secretion of HMGB1 is required for the migration of maturing dendritic cells. J Leukoc Biol. 2007;81:84-91.

57. Orlova W, Choi EY, Xie C, Chavakis E, Bierhaus A, Ihanus E, et al. A novel pathway of HMGB1-mediated inflammatory cell recruitment that requires Mac-1-integrin. EMBO J. 2007;26:1129-39.

58. Degryse B, Bonaldi T, Scaffidi P, Muller S, Resnati M, Sanvito F, et al. The high mobility group HMG boxes of the nuclear protein HMG1 induce chemotaxis and cytoskeleton reorganization in rat smooth muscle cells. J Cell Biol. 2001;152:1197-206.

59. Degryse B, de Virgilio M. The nuclear protein HMGB1, a new kind of chemokine? FEBS Lett. 2003;553:11-7.

60. Yu M, Wang H, Ding A, Golenbock DT, Latz E, Czura CJ, et al. HMGB1 signals through Toll-like receptor TLR4 and TLR2. Shock. 2006;26:174-9.

61. Ha T, Xia Y, Liu X, Lu C, Liu L, Kelley J, et al. Glucan phosphate attenuates myocardial HMGB1 translocation in severe sepsis through inhibiting NF-kappaB activation. Am J Physiol Heart Circ Physiol. 2011;301:H848-55.

62. Xiang $M$, Shi X, Li Y, XU J, Yin L, Xiao G, et al. Hemorrhagic shock activation of NLRP3 inflammasome in lung endothelial cells. J Immunol. 2011;187:4809-17.
63. Chen GY, Tang J, Zheng P, Liu Y. CD24 and Siglec-10 selectively repress tissue damage-induced immune responses. Science. 2009;323:1722-5.

64. Abeyama K, Stern DM, Ito Y, Kawahara K, Yoshimoto Y, Tanaka M, et al. The N-terminal domain of thrombomodulin sequesters high-mobility group-B1 protein, a novel antiinflammatory mechanism. J Clin Invest. 2005;115:1267-74.

65. Salmivirta M, Rauvala H, Elenius K, Jalkanen M. Neurite growth-promoting protein amphoterin, p30 binds syndecan. Exp Cell Res. 1992;200:444-51.

66. Yang H, Ochani M, Li J, Qiang X, Tanovic M, Harris HE, et al. Reversing established sepsis with antagonists of endogenous high-mobility group box 1. Proc Natl Acad Sci U S A. 2004;101:296-301.

67. Wang H, Yang H, Czura CJ, Sama AE, Tracey KJ. HMGB1 as a Late Mediator of Lethal Systemic Inflammation. Am J Respir Crit Care Med. 2001;164:1768-73.

68. Abraham E, Arcaroli J, Carmody A, Wang H, Tracey KJ. HMG-1 as a mediator of acute lung inflammation. J Immunol. 2000;165:2950-4.

69. Suda K, Kitagawa Y, Ozawa S, Saikawa Y, Ueda M, Ebina M, et al. Anti-highmobility group box chromosomal protein 1 antibodies improve survival of rats with sepsis. World J Surg. 2006;30:1755-62.

70. Ye C, Choi JG, Abraham S, Wu H, Diaz D, Terreros D, et al. Human macrophage and dendritic cell-specific silencing of high-mobility group protein B1 ameliorates sepsis in a humanized mouse model. Proc Natl Acad Sci U S A. 2012;109:21052-7.

71. Wang $H$, Liao $H$, Ochani M, Justiniani M, Lin X, Yang L, et al. Cholinergic agonists inhibit HMGB1 release and improve survival in experimental sepsis. Nat Med. 2004;10:1216-21.

72. Li W, Ashok M, Li J, Yang H, Sama AE, Wang H. A Major Ingredient of Green Tea Rescues Mice from Lethal Sepsis Partly by Inhibiting HMGB1. PLoS One. 2007:2:e1153.

73. Li W, Li J, Ashok M, Wu R, Chen D, Yang L, et al. A cardiovascular drug rescues mice from lethal sepsis by selectively attenuating a late-acting proinflammatory mediator, high mobility group box 1. J Immunol. 2007;178:3856-64.

74. Valdes-Ferrer SI, Rosas-Ballina M, Olofsson PS, Lu B, Dancho ME, Li J, et al. High-mobility group box 1 mediates persistent splenocyte priming in sepsis survivors: evidence from a murine model. Shock. 2013;40:492-5.

75. Sursal T, Stearns-Kurosawa DJ, Itagaki K, Oh SY, Sun S, Kurosawa S, et al. Plasma bacterial and mitochondrial DNA distinguish bacterial sepsis from sterile systemic inflammatory response syndrome and quantify inflammatory tissue injury in nonhuman primates. Shock. 2013;39:55-62.

76. Vincent JL, Opal SM, Marshall JC, Tracey KJ. Sepsis definitions: time for change. Lancet. 2013;381:774-5

77. Zhu S, Li W, Ward MF, Sama AE, Wang H. High mobility group box 1 protein as a potential drug target for infection- and injury-elicited inflammation. Inflamm Allergy Drug Targets. 2010;9:60-72.

78. Wu H, Ma J, Wang P, Corpuz TM, Panchapakesan U, Wyburn KR, et al. HMGB1 contributes to kidney ischemia reperfusion injury. J Am Soc Nephrol. 2010;21:1878-90.

79. Qiu J, Nishimura M, Wang Y, Sims JR, Qiu S, Savitz SI, et al. Early release of HMGB-1 from neurons after the onset of brain ischemia. J Cereb Blood Flow Metab. 2008;28:927-38

80. Okuma Y, Liu K, Wake H, Zhang J, Maruo T, Date I, et al. Anti-high mobility group box-1 antibody therapy for traumatic brain injury. Ann Neurol. 2012:72:373-84.

81. Shimazaki J, Matsumoto N, Ogura H, Muroya T, Kuwagata Y, Nakagawa J, et al. Systemic involvement of high-mobility group box 1 protein and therapeutic effect of anti-high-mobility group box 1 protein antibody in a rat model of crush injury. Shock. 2012;37:634-8.

82. Yang R, Zhang S, Cotoia A, Oksala N, Zhu S, Tenhunen J. High mobility group B1 impairs hepatocyte regeneration in acetaminophen hepatotoxicity. BMC Gastroenterol. 2012;12:45. doi:10.1186/1471-230X-12-45.

83. Nadatani $Y$, Watanabe T, Tanigawa T, Machida H, Okazaki H, Yamagami H, et al. High mobility group box 1 promotes small intestinal damage induced by nonsteroidal anti-inflammatory drugs through Toll-like receptor 4. Am J Pathol. 2012;181:98-110.

84. Hirata Y, Kurobe H, Higashida M, Fukuda D, Shimabukuro M, Tanaka K, et al. HMGB1 plays a critical role in vascular inflammation and lesion formation via toll-like receptor 9. Atherosclerosis. 2013;231:227-33.

85. Nadatani Y, Watanabe T, Tanigawa T, Ohkawa F, Takeda S, Higashimori A et al. High-Mobility Group Box 1 Inhibits Gastric Ulcer Healing through Toll-Like Receptor 4 and Receptor for Advanced Glycation End Products. PLoS One. 2013;8:e80130. 
86. Patel VS, Sitapara RA, Gore A, Phan B, Sharma L, Sampat V, et al. High Mobility Group Box-1 mediates hyperoxia-induced impairment of Pseudomonas aeruginosa clearance and inflammatory lung injury in mice. Am J Respir Cell Mol Biol. 2013:48:280-7.

87. Wu A, He L, Long W, Zhou Q, Zhu S, Wang P, et al. Novel mechanisms of herbal therapies for inhibiting HMGB1 secretion or action. EvidBasedComplement Alternat Med. 2015;2015:456305.

88. Wang H, Li W, Li J, Rendon-Mitchell B, Ochani M, Ashok M, et al. The aqueous extract of a popular herbal nutrient supplement, Angelica sinensis, protects mice against lethal endotoxemia and sepsis. J Nutr. 2006;136:360-5

89. Zhu S, Li W, Li J, Jundoria A, Sama AE, Wang H. It Is Not Just Folklore: The Aqueous Extract of Mung Bean Coat Is Protective against Sepsis. Evid Based Complement Alternat Med. 2012;2012:498467. doi:10.1155/2012/498467.

90. Okamoto T, Kanda T. Glycyrrhizin protects mice from concanavalin Ainduced hepatitis without affecting cytokine expression. Int J Mol Med 1999:4:149-52.

91. Mabuchi A, Wake K, Marlini M, Watanabe H, Wheatley AM. Protection by glycyrrhizin against warm ischemia-reperfusion-induced cellular injury and derangement of the microcirculatory blood flow in the rat liver. Microcirculation. 2009;16:364-76.

92. Ogiku M, Kono H, Hara M, Tsuchiya M, Fujii H. Glycyrrhizin prevents liver injury by inhibition of high-mobility group box 1 production by Kupffer cells after ischemia-reperfusion in rats. J Pharmacol Exp Ther. 2011;339:93-8.

93. Kuroda N, Inoue K, Ikeda T, Hara Y, Wake K, Sato T. Apoptotic response through a high mobility box 1 protein-dependent mechanism in LPS/GalN-induced mouse liver failure and glycyrrhizin-mediated inhibition. PLoS One. 2014;9:e92884

94. Wang X, Sun R, Wei H, Tian Z. High-mobility group box 1 HMGB1-Toll-like receptor TLR4-interleukin IL-23-IL-17A axis in drug-induced damage-associated lethal hepatitis: Interaction of gammadelta T cells with macrophages. Hepatology. 2013;57:373-84.

95. Sakamoto R, Okano M, Takena H, Ohtsuki K. Inhibitory effect of glycyrrhizin on the phosphorylation and DNA-binding abilities of high mobility group proteins 1 and 2 in vitro. Biol Pharm Bull. 2001;24:906-11.

96. Mollica L, De Marchis F, Spitaleri A, Dallacosta C, Pennacchini D, Zamai M, et al. Glycyrrhizin binds to high-mobility group box 1 protein and inhibits its cytokine activities. Chem Biol. 2007;14:431-41.

97. Yamaguchi H, Kidachi Y, Kamiie K, Noshita T, Umetsu H. Structural insight into the ligand-receptor interaction between glycyrrhetinic acid GA and the high-mobility group protein B1 HMGB1-DNA complex. Bioinformation. 2012:8:1147-53.

98. Shearman DJ, Hetzel D. The medical management of peptic ulcer. Annu Rev Med. 1979;30:61-79.

99. Ma W, Hui H, Pelegrin P, Surprenant A. Pharmacological characterization of pannexin-1 currents expressed in mammalian cells. J Pharmacol Exp Ther. 2009;328:409-18.

100. Poornima V, Madhupriya M, Kootar S, Sujatha G, Kumar A, Bera AK. P2X7 receptor-pannexin 1 hemichannel association: effect of extracellular calcium on membrane permeabilization. J Mol Neurosci. 2012;46:585-94.

101. Li W, Li J, Sama AE, Wang H. Carbenoxolone Blocks Endotoxin-Induced Protein Kinase R PKR Activation and High Mobility Group Box 1 HMGB1 Release. Mol Med. 2013;19:203-11.

102. Thompson RJ, Zhou N, MacVicar BA. Ischemia opens neuronal gap junction hemichannels. Science. 2006:312:924-7.

103. Reigada D, Lu W, Zhang M, Mitchell CH. Elevated pressure triggers a physiological release of ATP from the retina: Possible role for pannexin hemichannels. Neuroscience. 2008;157:396-404.

104. Sridharan M, Adderley SP, Bowles EA, Egan TM, Stephenson AH, Ellsworth $M L$, et al. Pannexin 1 is the conduit for low oxygen tension-induced ATP release from human erythrocytes. Am J Physiol Heart Circ Physiol. 2010;299:H1146-52.

105. Surprenant A, Rassendren F, Kawashima E, North RA, Buell G. The cytolytic $\mathrm{P} 2 \mathrm{Z}$ receptor for extracellular ATP identified as a $\mathrm{P} 2 \mathrm{X}$ receptor $\mathrm{P} 2 \mathrm{X} 7$. Science. 1996;272:735-8.

106. Perregaux DG, McNiff $P$, Laliberte $R$, Conklyn M, Gabel CA. ATP acts as an agonist to promote stimulus-induced secretion of IL-1 beta and IL-18 in human blood. J Immunol. 2000;165:4615-23.

107. Li W, Zhu S, Li J, Assa A, Jundoria A, Xu J, et al. EGCG stimulates autophagy and reduces cytoplasmic HMGB1 levels in endotoxin-stimulated macrophages. Biochem Pharmacol. 2011;81:1152-63.
108. Zhou J, Farah BL, Sinha RA, Wu Y, Singh BK, Bay BH, et al. Epigallocatechin3-gallate EGCG, a green tea polyphenol, stimulates hepatic autophagy and lipid clearance. PLoS One. 2014;9:e87161.

109. Li CP, Yao J, Tao ZF, Li XM, Jiang Q, Yan B. Epigallocatechin-gallate EGCG regulates autophagy in human retinal pigment epithelial cells: a potential role for reducing UVB light-induced retinal damage. Biochem Biophys Res Commun. 2013:438:739-45.

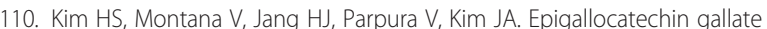
EGCG stimulates autophagy in vascular endothelial cells: a potential role for reducing lipid accumulation. J Biol Chem. 2013;288:22693-705.

111. Tang D, Kang R, Livesey KM, Cheh CW, Farkas A, Loughran P, et al. Endogenous HMGB1 regulates autophagy. J Cell Biol. 2010;190:881-92.

112. Kang R, Livesey KM, Zeh HJ, Loze MT, Tang D. HMGB1: A novel Beclin 1binding protein active in autophagy. Autophagy. 2010;6:1209-11.

113. Zhang Y, Li W, Zhu S, Jundoria A, Li J, Yang H, et al. Tanshinone IIA sodium sulfonate facilitates endocytic HMGB1 uptake. Biochem Pharmacol. 2012;84:1492-500.

114. Gordon PB, Seglen PO. Prelysosomal convergence of autophagic and endocytic pathways. Biochem Biophys Res Commun. 1988;151:40-7.

115. Klionsky DJ. Autophagy: from phenomenology to molecular understanding in less than a decade. Nat Rev Mol Cell Biol. 2007;8:931-7.

116. Berg TO, Fengsrud M, Stromhaug PE, Berg T, Seglen PO. Isolation and characterization of rat liver amphisomes. Evidence for fusion of autophagosomes with both early and late endosomes. J Biol Chem. 1998;273:21883-92.

117. Lefering R, Neugebauer EA. Steroid controversy in sepsis and septic shock: a meta-analysis. Crit Care Med. 1995;23:1294-303.

118. Annane D, Sebille V, Charpentier C, Bollaert PE, Francois B, Korach JM, et al Effect of treatment with low doses of hydrocortisone and fludrocortisone on mortality in patients with septic shock. JAMA. 2002;288:862-71.

119. Sprung CL, Annane D, Keh D, Moreno R, Singer M, Freivogel $K$, et al. Hydrocortisone therapy for patients with septic shock. N Engl J Med. 2008;358:111-4.

120. Rivers E, Nguyen B, Havstad S, Ressler J, Muzzin A, Knoblich B, et al. Early goal-directed therapy in the treatment of severe sepsis and septic shock. $N$ Engl J Med. 2001;345:1368-77.

121. Russell JA, Walley KR, Singer J, Gordon AC, Hebert PC, Cooper DJ, et al. Vasopressin versus norepinephrine infusion in patients with septic shock. $\mathrm{N}$ Engl J Med. 2008;358:877-87.

122. Zhao L, Li W, Zhu S, Tsai S, Li J, Tracey KJ, et al. Green tea catechins quench the fluorescence of bacteria-conjugated Alexa fluor dyes. Inflamm Allergy Drug Targets. 2013;12:308-14.

123. He XD, Wang Y, Wu Q, Wang HX, Chen ZD, Zheng RS, et al. Xuebijing Protects Rats from Sepsis Challenged with Acinetobacter baumannii by Promoting Annexin A1 Expression and Inhibiting Proinflammatory Cytokines Secretion. Evid Based Complement Alternat Med. 2013;2013:804940. doi:10.1155/2013/804940.

124. Yin Q, Li C. Treatment effects of xuebijing injection in severe septic patients with disseminated intravascular coagulation. Evid Based Complement Alternat Med. 2014;2014:949254. doi:10.1155/2014/949254.

125. Qi F, Liang ZX, She DY, Yan GT, Chen LA. A clinical study on the effects and mechanism of xuebijing injection in severe pneumonia patients. J Tradit Chin Med. 2011:31:46-9.

126. Nakahira K, Haspel JA, Rathinam VA, Lee SJ, Dolinay T, Lam HC, et al. Autophagy proteins regulate innate immune responses by inhibiting the release of mitochondrial DNA mediated by the NALP3 inflammasome. Nat Immunol. 2011;12:222-30.

127. Shi CS, Shenderov K, Huang NN, Kabat J, Abu-Asab M, Fitzgerald KA, et al. Activation of autophagy by inflammatory signals limits IL-1 beta production by targeting ubiquitinated inflammasomes for destruction. Nat Immunol. 2012;13:255-63.

128. Ziegler EJ, Fisher Jr CJ, Sprung CL, Straube RC, Sadoff JC, Foulke GE, et al. Treatment of gram-negative bacteremia and septic shock with $\mathrm{HA}-1 \mathrm{~A}$ human monoclonal antibody against endotoxin. A randomized, double-blind, placebo-controlled trial. The HA-1A Sepsis Study Group. N Engl J Med. 1991;324:429-36.

129. Opal SM, Laterre PF, Francois B, LaRosa SP, Angus DC, Mira JP, et al. Effect of eritoran, an antagonist of MD2-TLR4, on mortality in patients with severe sepsis: the ACCESS randomized trial. JAMA. 2013;309:1154-62.

130. Feldmann M, Maini RN. Anti-TNF alpha therapy of rheumatoid arthritis: what have we learned? Annu Rev Immunol. 2001;19:163-96. 
131. Weber GF, Chousterman BG, He S, Fenn AM, Nairz M, Anzai A, et al. Interleukin-3 amplifies acute inflammation and is a potential therapeutic target in sepsis. Science. 2015;347:1260-5.

132. Yang $H$, Wang $H$, Ju Z, Ragab AA, Lundbäck P, Long W, et al. MD-2 is required for disulfide HMGB1-dependent TLR4 signaling. J Exp Med. 2015;212:5-14.

Submit your next manuscript to BioMed Central and take full advantage of:

- Convenient online submission

- Thorough peer review

- No space constraints or color figure charges

- Immediate publication on acceptance

- Inclusion in PubMed, CAS, Scopus and Google Scholar

- Research which is freely available for redistribution 